\title{
Production of 3-hydroxy- $\gamma$-decalactone, the precursor of two decenolides with flavouring properties, by the yeast Yarrowia lipolytica
}

\author{
Erandi Escamilla García ${ }^{a}$, Mario Aguedo ${ }^{b}$, Nelma Gomes ${ }^{b}$, Armelle Choquet ${ }^{\mathrm{a}}$, Isabel Belo ${ }^{\mathrm{b}}$, \\ José Antonio Teixeira ${ }^{\mathrm{b}}$, Jean-Marc Belin ${ }^{\mathrm{a}}$, Yves Wachéa, ${ }^{\mathrm{a}, *}$ \\ a Laboratoire de GPMA, IFR 92, Université de Bourgogne, ENSBANA, 1 esplanade Erasme, 21000 Dijon, France \\ ${ }^{\mathrm{b}}$ Institute for Biotechnology and Bioengineering (IBB), Centre for Biological Engineering, Universidade do Minho, \\ Campus de Gualtar, 4710-057 Braga, Portugal
}

\section{A R T I C L E I N F O}

\section{Article history:}

Received 15 April 2008

Received in revised form 6 June 2008

Accepted 13 June 2008

Available online 21 June 2008

\section{Keywords}

3-Hydroxy- $\gamma$-decalactone

$\beta$-Oxidation fluxes

Oxygen

Yarrowia lipolytica

\begin{abstract}
A B S T R A C T
3-Hydroxy- $\gamma$-decalactone is the precursor of dec- 2 and dec-3-en-4-olides which are valuable aroma compounds not yet produced. To promote the accumulation of this lactone, the yeast Yarrowia lipolytica was placed in different environmental conditions aiming at altering $\beta$-oxidation fluxes. The concentration of substrate, $\mathrm{pH}$, aeration and dissolved oxygen level were modified. We observed an important accumulation at low aeration ( 0.40 molar yields) and, to a lesser extent, at lower $\mathrm{pH}(0.15)$. As oxygen played a key-role, we evaluated its effect at fixed dissolved oxygen and at the $\mathrm{pH}$ which was the most favourable to the biotransformation ( $\mathrm{pH} 4.5$ ). At $5 \%$ and $30 \%$ dissolved oxygen, yields reached 0.50 . $\beta$-Oxidation fluxes are very dependent on the presence of oxygen and conditions of accumulation of 3-hydroxy- $\gamma$-decalactone with very high yields were identified. These results are an important step in the production of the two decenolides. Moreover, they show the high dependence of $\beta$-oxidation fluxes on environmental conditions and relate these conditions to the accumulation of intermediates, results that are of interest to all the processes using yeast on lipids or alkanes.
\end{abstract}

(c) 2008 Elsevier B.V. All rights reserved.

\section{Introduction}

In yeast, the catabolism of methyl ricinoleate results in the accumulation of the popular flavouring compound $\gamma$-decalactone $[1,2]$. With some yeast species, other lactones accumulate, in particular dec-2-en-4-olide and dec-3-en-4-olide [3,4] (Fig. 1). These two decenolides are powerful aroma compounds exhibiting fruity or mushroom notes and they result from the degradation of 3-hydroxy- $\gamma$-decalactone [3]. Due to their interesting sensorial properties, these compounds could be of great interest as flavouring compounds, but they are not yet produced. The whole world of flavours and fragrances is currently seeking new compounds that could be used in aroma formulations (see for instance recent works on the production of raspberry ketone, 6-pentyl-alphapyrone, ionones, dihydroactinidiolide, damascenone, etc. [5-11]). The two decenolides can already accumulate, although in very low amounts, with the yeast Yarrowia lipolytica [3,4]. Both compounds result from the dehydration of 3-hydroxy- $\gamma$-decalactone, a compound accumulating after hydrolysis of an acyl-CoA $\beta$-oxidation

\footnotetext{
* Corresponding author. Tel.: +33 380396680 .

E-mail address: ywache@u-bourgogne.fr (Y. Waché).
}

intermediate (Fig. 1). The accumulation of this hydroxylated lactone has already been studied due to its importance as a by-product competing with $\gamma$-decalactone and thus involved in a decrease in yields. It has been shown that strains with decreased acyl-CoA oxidase activity (the first activity in the $\beta$-oxidation cycle) accumulated less 3-hydroxy- $\gamma$-decalactone [4] and that oxygen pressure or $K_{\mathrm{L}} a$ had an impact on accumulation of both lactones [12,13]. In the conditions the most favourable to $\gamma$-decalactone, $1 \%$ molar was "lost" in 3-hydroxy- $\gamma$-decalactone and this percentage reached $6-8 \%$ at $K_{\mathrm{L}} a=120 \mathrm{~h}^{-1}$ and $0.5 \mathrm{MPa}$ air pressure, respectively. Following this work, a response surface methodology study was carried out to identify experimental domains for which $\gamma$-decalactone accumulated but not 3-hydroxy- $\gamma$-decalactone [14]. This work with modification of aeration and $\mathrm{pH}$ confirmed results obtained with variations of the acyl-CoA oxidase activity [15] showing that for conditions restricting growth, $\gamma$-decalactone accumulated but not 3-hydroxy- $\gamma$-decalactone.

The present study aims at increasing the production of 3hydroxy- $\gamma$-decalactone, the precursor of dec-2-en-4-olide and dec-3-en-4-olide. In that goal, environmental conditions were modified in an experimental domain that only slightly altered cell growth but with low $K_{\mathrm{L}} a$ or dissolved oxygen to stimulate the accumulation of 3-hydroxy- $\gamma$-decalactone which reached, in that conditions, 0.50 molar yields. 


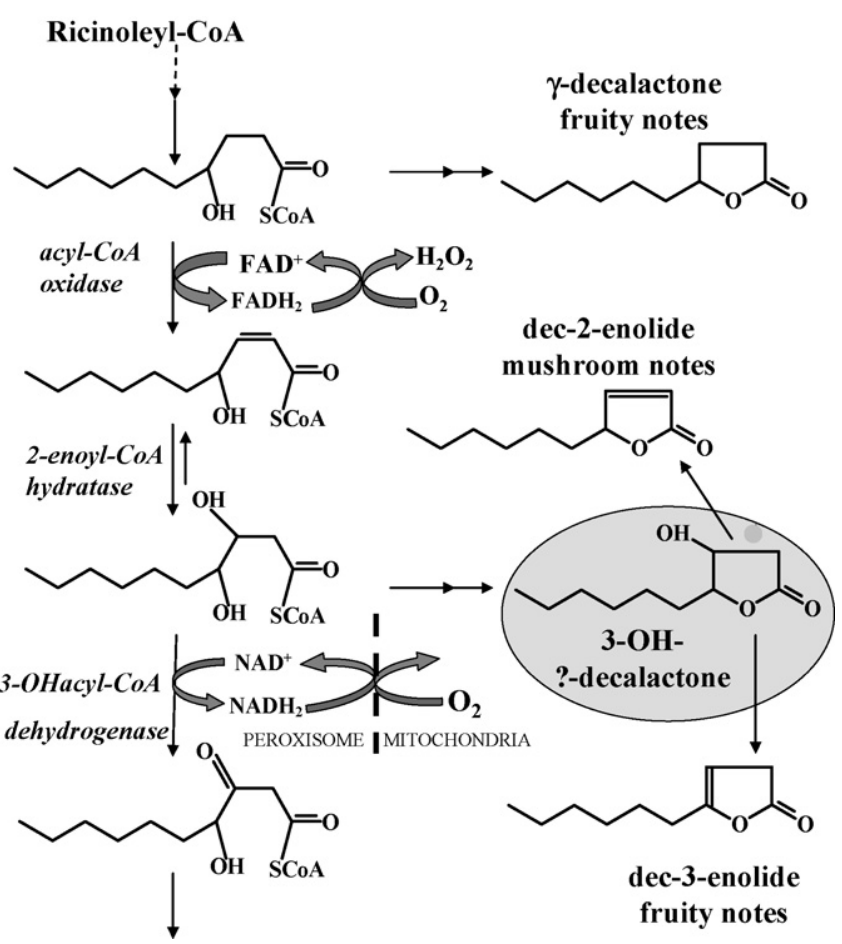

Fig. 1. $\beta$-Oxidation loop at the $\mathrm{C} 10$ level of the degradation of ricinoleyl-CoA, enzymatic activities, cofactor requirements and reaction products (adapted from Waché et al. [4]).

\section{Materials and methods}

\subsection{Strain and culture conditions}

The strain used in this study was Y. lipolytica W29 (ATCC 20460). Preculture was carried out for $48 \mathrm{~h}$ on YPDA (Yeast Peptone Dextrose Agar: $20 \mathrm{~g} / \mathrm{l}$ glucose, $20 \mathrm{~g} / \mathrm{l}$ tryptone pancreatic digest of casein, $10 \mathrm{~g} / \mathrm{l}$ yeast extract and $15 \mathrm{~g} / \mathrm{l}$ agar) at $27^{\circ} \mathrm{C}$ and cells were used to inoculate a $500 \mathrm{ml}$ baffled Erlenmeyer flask containing $200 \mathrm{ml}$ of YPD medium, to an $A_{600}=0.25\left(6 \times 10^{6} \mathrm{cells} / \mathrm{ml}\right)$. Flasks were shaken at $140 \mathrm{rpm}$ for $18 \mathrm{~h}$ until the cultures reached the late logarithmic growth phase. Cells were harvested $(10,000 \times g$, $5 \mathrm{~min}$ ), washed twice with phosphate buffer ( $50 \mathrm{mM}, \mathrm{pH} 7.4)$ and resuspended in methyl ricinoleate (MR) medium [16] containing $5 \mathrm{~g} / \mathrm{l}$ methyl ricinoleate, $6.7 \mathrm{~g} / \mathrm{l}$ yeast nitrogen base, $5 \mathrm{~g} / 1 \mathrm{NH}_{4} \mathrm{Cl}$ and $0.2 \mathrm{~g} / \mathrm{l}$ Tween 80 . In this emulsioned medium, lipids absorbed light and cell growth was therefore monitored by counting on a Malassez cell. For aeration studies, the culture was carried out in 1.41 volume in a 2-1 Setric reactor (NBS, Toulouse, France) with an agitation of $300 \mathrm{rpm}$ and oxygen transfer coefficients, $K_{\mathrm{L}} a$ (evaluated according to the gassing-in method [17]), comprised between $8.1 \mathrm{~h}^{-1}$ (aeration: $10 \mathrm{l} / \mathrm{h}$ or $0.11 \mathrm{vvm}$ (volume of air per volume of reactor per minute)) and $37.0 \mathrm{~h}^{-1}$ (aeration: $160 \mathrm{l} / \mathrm{h}$ or $1.76 \mathrm{vvm}$ ). For $\mathrm{pH}$ and substrate concentration experiments, cells were resuspended after preculture in YPD in a $500 \mathrm{ml}$ baffled Erlenmeyer flask containing $200 \mathrm{ml}$ of the MR medium modified as follows: for $\mathrm{pH}$, citrate buffer ( $100 \mathrm{mM})$ at $\mathrm{pH} 3.0,4.5$ or 6.0 was added and the $\mathrm{pH}$ was checked at the end of the culture; and for substrate concentration, the initial concentration of methyl ricinoleate was equal to $5 \mathrm{~g} / \mathrm{l}, 15 \mathrm{~g} / \mathrm{l}$ or $30 \mathrm{~g} / \mathrm{l}$. All chemicals were purchased from Sigma/Aldrich (Saint-Quentin Fallavier, France) except methyl ricinoleate (Stéarinerie Dubois, Boulogne, France). Methyl ricinoleate is actually methylated castor oil which contains about $90 \%$ methyl ricinoleate in addition to other fatty acid methyl esters which were not hydroxylated and thus could not give rise to lactones [1,2]. For dissolved oxygen experiments, a 2-1 bioreactor (Autoclavable Benchtop Fermenter Type R'ALF, Bioengineering AG, Wald, Switzerland) containing 1.41 of MR medium was used. Dissolved oxygen concentrations $(5 \%, 30 \%$ and $90 \%$ of saturation) were controlled with a cascade control via stirrer speed and aeration valve. The gas output was condensed at $4{ }^{\circ} \mathrm{C}$ and the culture $\mathrm{pH}$ was set to 4.45 $( \pm 0.05)$ with $\mathrm{NaOH}$ and $\mathrm{HCl}$.

\subsection{Lactones analyses}

Analyses were carried out on $1.5 \mathrm{ml}$ samples collected regularly from the culture medium. These samples were prepared and analysed as previously described [4]: $10 \mu \mathrm{l} \mathrm{HCl} \mathrm{(36 \% ,} \mathrm{w/v)} \mathrm{were} \mathrm{added}$ to stop the metabolism and to achieve the complete lactonisation of 4-hydroxy acids, they were centrifuged, $\gamma$-undecalactone (internal standard) was added and the mixture was extracted with diethyl ether. The organic phase was analysed in a HP6890 gas chromatograph (Agilent Technologies, Lyon, France) with a HP-INNOWax capillary column (Agilent $30 \mathrm{~m} \times 320 \mu \mathrm{m} \times 0.25 \mu \mathrm{m}$ ) with $\mathrm{N}_{2}$ as a carrier gas at a linear flow rate of $4.3 \mathrm{ml} / \mathrm{min}$. The split injector (split ratio, 7.1:1) temperature was set to $250^{\circ} \mathrm{C}$ and the flame ionization detector, to $300^{\circ} \mathrm{C}$. The oven temperature increased from $60^{\circ} \mathrm{C}$ to $145^{\circ} \mathrm{C}$ at $5^{\circ} \mathrm{C} / \mathrm{min}$, and finally at $2^{\circ} \mathrm{C} / \mathrm{min}$ to reach $215^{\circ} \mathrm{C}$ [18]. Mass spectra were obtained through a GC-MS analysis with a HP5890 gas chromatograph (Agilent) with He as the carrier gas and a HP MSD 5970 mass spectrometer (Agilent) using ionization by a $70 \mathrm{eV}$ electronic impact.

Results concerning the production of lactones are given in molar yields: $Y=$ concentration of lactone in the medium (Mol)/initial concentration of methyl ricinoleate (Mol).

All data presented are means of at least three independent experiments.

\section{Results}

\subsection{Effect of $p H$}

Y. lipolytica cells were grown with $5 \mathrm{~g} / \mathrm{l}$ methyl ricinoleate and citrate buffer $(100 \mathrm{mM})$ at $\mathrm{pH} 3,4.5$ and 6 . Time courses of methyl ricinoleate conversion into lactones are presented in Fig. 2 . The conversion to 3-hydroxy- $\gamma$-decalactone began after $10 \mathrm{~h}$ and reached the maximum conversion after $40 \mathrm{~h}$ at $\mathrm{pH} 6,50 \mathrm{~h}$ at $\mathrm{pH} 4.5$ and $75 \mathrm{~h}$ at $\mathrm{pH} 3$ (Fig. 3a). The maximum molar conversion into this lactone was of about 0.15 at $\mathrm{pH} 3$ and 4.5 and of 0.10 at $\mathrm{pH}$ 6. No significant degradation of this compound was detected during the $80 \mathrm{~h}$ of the culture. $\gamma$-Decalactone conversion (Fig. 3c) increased until $24 \mathrm{~h}$ at $\mathrm{pH} 6$ and 4.5 and until $50 \mathrm{~h}$ at $\mathrm{pH} 3$, yields reaching 0.06 , 0.02 and 0.02 , respectively. The concentrations in the culture then decreased rapidly at near neutral $\mathrm{pH}$ but only slowly in more acidic conditions. The kinetics of accumulation of the two decenolides (Fig. $2 \mathrm{~b}$ and d) were comparable to those of the 3-hydroxy-lactone and the maximal accumulation occurred later than the one of $\gamma$ decalactone and yields reached about 0.05 for dec-2-enolide and 0.03 for dec-3-enolide. The effect of $\mathrm{pH}$ on the accumulation of the two decenolides was not significant.

\subsection{Effect of substrate concentration}

For non-regulated $\mathrm{pH}$ conditions with the same amount of methyl ricinoleate, the amount of 3-hydroxy- $\gamma$-decalactone was in the same order of magnitude as in $\mathrm{pH}$-regulated cultures $(Y=0.10)$ whereas the one of $\gamma$-decalactone accumulated was very small $(Y=0.01)$ (Fig. 3). The molar conversion was not greatly modified by the initial concentration of methyl ricinoleate and was always about 

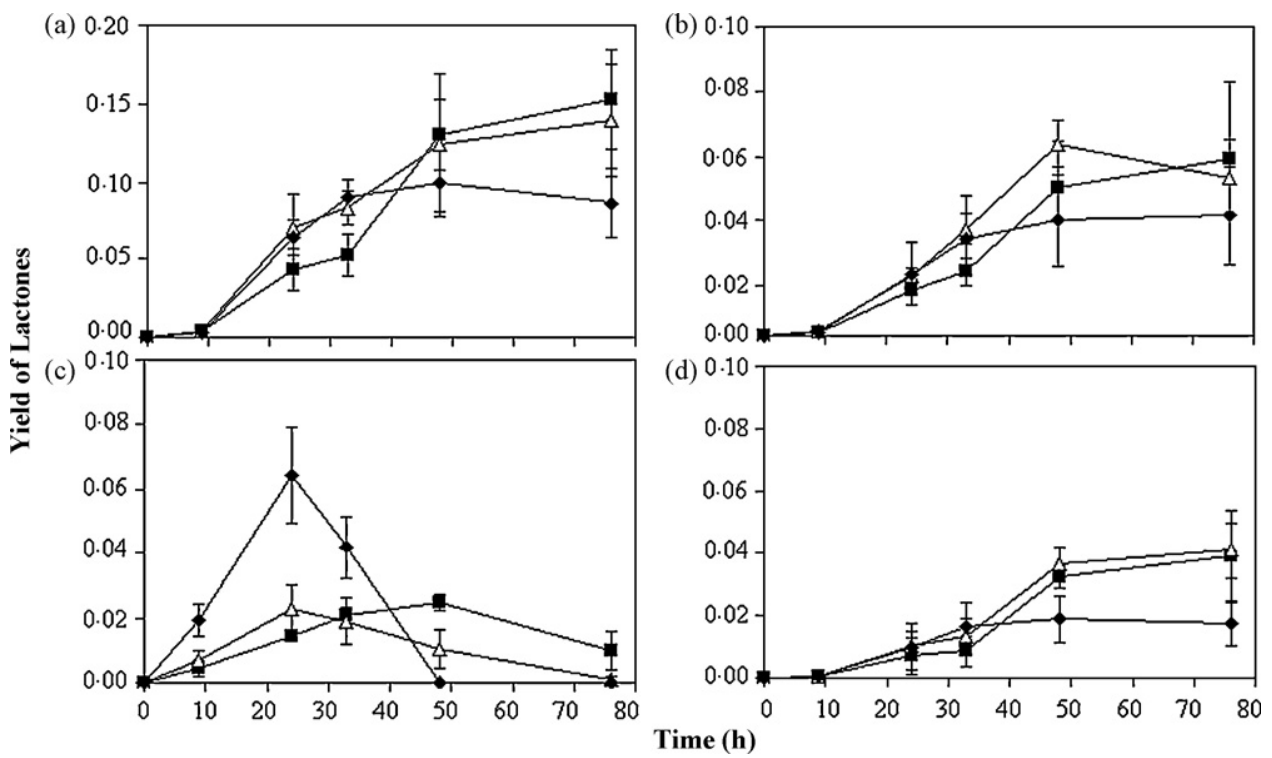

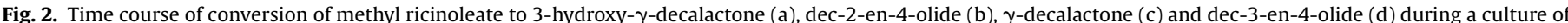

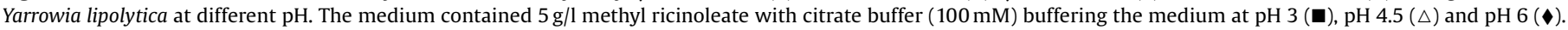
The mean values were calculated from three independent experiments.

0.10-0.12 for 3-hydroxy- $\gamma$-decalactone but this yield was reached earlier for lower substrate concentrations $(30 \mathrm{~h}$ for $5 \mathrm{~g} / \mathrm{l}, 50 \mathrm{~h}$ for $15 \mathrm{~g} / \mathrm{l}$ and $80 \mathrm{~h}$ for $30 \mathrm{~g} / \mathrm{l}$ ). For $\gamma$-decalactone, it reached 0.02 with $15 \mathrm{~g} / \mathrm{l}$ but only 0.01 with $30 \mathrm{~g} / \mathrm{l}$. However, with the highest concentrations of methyl ricinoleate, 15 and $30 \mathrm{~g} / \mathrm{l}$, the degradation of $\gamma$-decalactone was limited maintaining yields at 0.007 at the end of the culture. The kinetics of conversion into decenolides were very similar to those of the 3-hydroxy-lactone with a conversion reaching earlier its final value for lower substrate concentrations.

\subsection{Effect of aeration}

In order to evaluate the effect of aeration on the accumulation of lactones, cells were grown in a $2-1$ bioreactor with various $K_{\mathrm{L}} a$ :
$37.0 \mathrm{~h}^{-1}, 26.4 \mathrm{~h}^{-1}$ and $8.1 \mathrm{~h}^{-1}$ (Fig. 4). In the three conditions, the dissolved oxygen level decreased during the log-growth phase to $\sim 70 \%$ for the highest aeration and to less than $20 \%$ for the lowest one. It increased afterwards to about $90 \%$. With $37.0 \mathrm{~h}^{-1}$, results were similar to those obtained in baffled Erlenmeyer flasks with yields reaching 0.12 for 3-hydroxy- $\gamma$-decalactone, about 0.03 for dec-2-enolide, 0.02 for dec-3-enolide and there was very little $\gamma$ decalactone accumulation (0.009). However, when decreasing $K_{\mathrm{L}} a$ to $26.4 \mathrm{~h}^{-1}$, the conversion ratio to 3-hydroxy- $\gamma$-decalactone did not change significantly at about 0.13 , contrary to $\gamma$-decalactone, for which the yield increased to 0.07 . Finally, for $8.1 \mathrm{~h}^{-1}$, maximum $\gamma$-decalactone was low (0.036) whereas the hydroxy-lactone was significantly higher, the yield reaching 0.44 at the end of the culture. Interestingly, the yields for the two decenolides were only $50 \%$
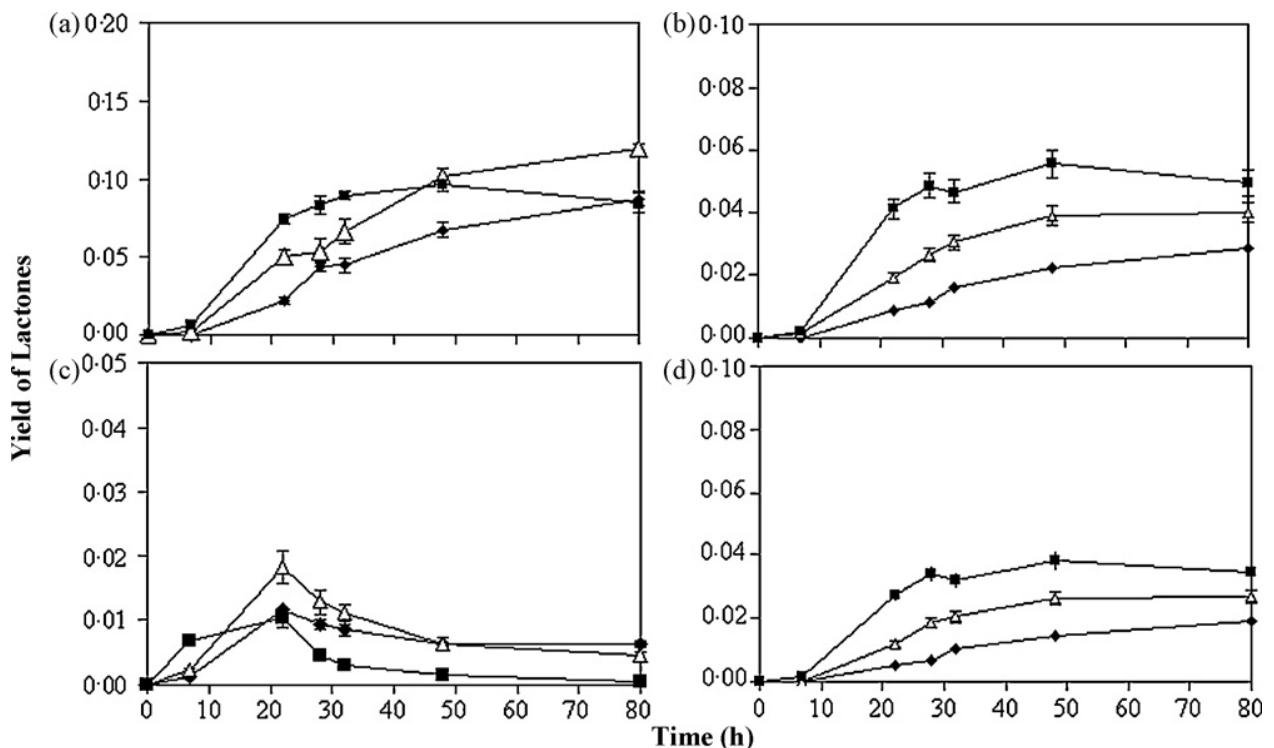

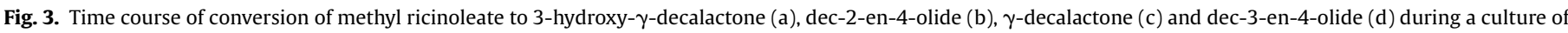

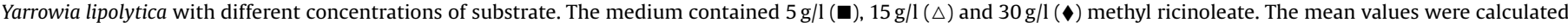
from three independent experiments. 

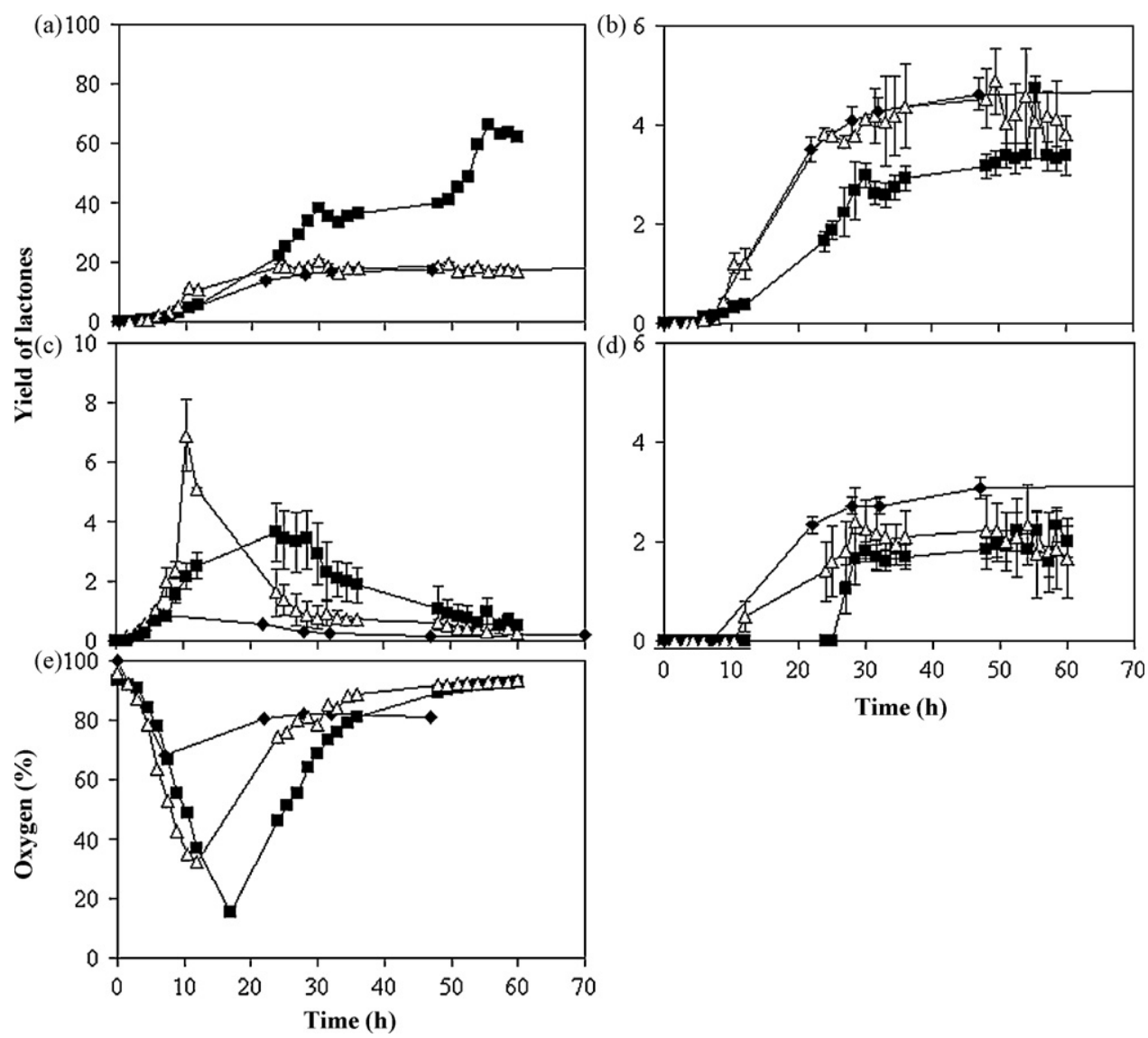

Fig. 4. Time course of conversion of methyl ricinoleate to 3-hydroxy- $\gamma$-decalactone (a), dec-2-en-4-olide (b), $\gamma$-decalactone (c) and dec-3-en-4-olide (d) during a culture

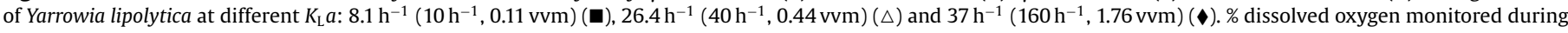
cultures (e). The mean values were calculated from three independent experiments.

higher at $8.1 \mathrm{~h}^{-1}$ than at $26.4 \mathrm{~h}^{-1}$ compared to the $450 \%$ difference for 3-hydroxy- $\gamma$-decalactone.

\subsection{Effect of dissolved oxygen}

The previous experiments showed that aeration was the parameter with the highest effect on the accumulation of 3 hydroxy- $\gamma$-decalactone. To specify its effect, cultures at fixed dissolved oxygen levels were carried out. For these experiments, the $\mathrm{pH}$ was set to its intermediate value $(\mathrm{pH} 4.45 \pm 0.05)$ and a substrate concentration of $5 \mathrm{~g} / \mathrm{l}$ was used.

Fig. 5 shows that maximal accumulations of 3-hydroxy- $\gamma$ decalactone were reached under lower dissolved oxygen (5\%). A rapid and constant increase in the concentration of 3-hydroxy- $\gamma$ decalactone occurred. After $45 \mathrm{~h}$ of culture, just after the maximal number of cells was reached $\left(3.1 \times 10^{7}\right.$ cells $/ \mathrm{ml}$ at $\left.42 \mathrm{~h}\right)$, yield reached 0.49 . For the culture with $30 \%$ of dissolved oxygen, the yield for 3-hydroxy- $\gamma$-decalactone reached almost the same maximum value $(0.43)$ but only after $74 \mathrm{~h}$. In this case, the accumulation taking place during growth was limited to 0.18 after $27 \mathrm{~h}$ (when the maximal number of cells was reached $\left(4 \times 10^{7}\right.$ cells $\left./ \mathrm{ml}\right)$. The lowest yield observed was of 0.17 in $24 \mathrm{~h}$, at $90 \%$ of dissolved oxygen. Accumulation took place during the growth phase reaching the highest value after $24 \mathrm{~h}$ of culture when the number of cells was the highest $\left(2.9 \times 10^{7}\right.$ cells $\left./ \mathrm{ml}\right)$. The yields for dec-2-en-4-olide were of 0.042 at $90 \%$ dissolved oxygen and increased to 0.057 at $5 \%$ dissolved oxygen. For dec-3-en-4-olide, they were of 0.017 at $90 \%$ and increased to 0.036 at $5 \%$ dissolved oxygen.

\section{Discussion}

In yeast, $\beta$-oxidation is the main pathway of degradation of fatty acids. It takes place in peroxisomes after the activation of these metabolites into acyl-CoA esters. Contrasting with the mitochondrial $\beta$-oxidation of superior eukaryotes, the extent of the peroxisomal degradation is usually limited to a few cycles although in vitro observations by Bartlett et al. [19] in mammal cells suggest that, at low substrate concentration, the degradation could be complete. During $\beta$-oxidation, metabolites can be excreted to the surrounding medium and the degradation may be completed when

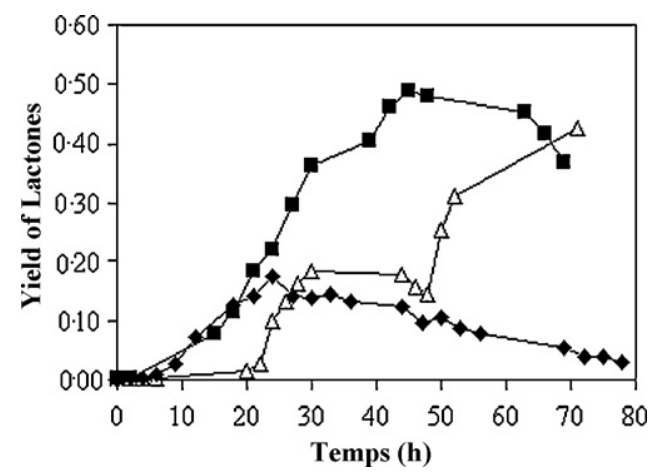

Fig. 5. Time course of conversion of methyl ricinoleate to 3-hydroxy- $\gamma$-decalactone during the culture of Y. lipolytica at $\mathrm{pH} 4.4$ and $(\boldsymbol{\square}) 5 \%,(\triangle) 30 \%$ and $(\bullet) 90 \%$ of dissolved oxygen. 
more favourable conditions are reached. Many factors may exhibit an effect on the extent of the degradation as for instance the equilibrium between the concentrations of fatty acid, acyl-CoA (both depending on the acyl-chain length), CoA, acetyl-CoA [19]. Moreover, the exit of metabolites can also be promoted by a deficiency or a low activity of one $\beta$-oxidation enzymes. These enzymes are active at each cycle of oxidation and a low activity may result in an exit after a limited number of cycles.

The acyl-CoA oxidase is generally considered as the enzyme exhibiting the lowest activity. From previous studies, we observed that decreasing this activity, which was possible by deleting genes coding for isoforms in Y. lipolytica, modified drastically the accumulation of lactones $[16,20]$. The strains for which the low acyl-CoA oxidase activity resulted in an altered growth, accumulated $\gamma$ decalactone (corresponding to an exit at the acyl-CoA oxidase level) but not 3-hydroxy- $\gamma$-decalactone (corresponding to an exit at the 3-hydroxyacyl-CoA dehydrogenase level), suggesting that the dehydrogenase activity was sufficient. In vitro, the activity of this enzyme is far higher than the one of acyl-CoA oxidase but in vivo, it is believed to be driven by the peroxisomal NADH/NAD ratio, a ratio which cannot be monitored in conditions corresponding to any metabolic reality [21,22]. A low dehydrogenase activity results in the accumulation of 3-hydroxy intermediates, which has already been observed in animal cells and which results in the accumulation of methyl ketone or alcohol in fermented cheese or sausages. Because of the barrier role played by the peroxisomal membrane $[23,24]$, the oxidation state of cofactors inside the peroxisome depends on the mitochondrial respiration through shuttle mechanisms involving organic acids of the glyoxylate cycle [25].

Fluxes of $\beta$-oxidation are thus quite complex and oxygen and $\mathrm{pH}$ were the environmental parameters showing the highest effect on this pathway. In particular, low aeration conditions altering significantly growth were related to a high accumulation of $\gamma$-decalactone [14]. The results of the present study, together with those of recent ones, show that aeration can be divided into four main domains just as the effect of acyl-CoA oxidase activity on this pathway has been divided into domains [15]. In the first one (observed by Escamilla García et al. [14]), very low oxygen levels inhibit acylCoA oxidase (oxygen is the co-substrate), limit $\beta$-oxidation and promote the accumulation of $\gamma$-decalactone. In the second domain (observed in this study), the aeration level is still low, but does not affect acyl-CoA oxidase activity. In this case, the impact would be on 3-hydroxyacyl-CoA dehydrogenase through the regeneration of NAD (respiration-dependent). In our study, this results in yields of 3-hydroxy- $\gamma$-decalactone reaching 0.50 . By increasing aeration, a third domain is reached in which $\beta$-oxidation is optimal and few intermediates accumulate. Finally, a fourth domain has been observed $[12,13]$ in which very high aeration disturb the $\beta$-oxidation fluxes resulting in slightly higher accumulation of 3hydroxy- $\gamma$-decalactone.

In our study, the first aiming at producing the two flavouring decenolides, it is possible to use this knowledge on $\beta$-oxidation fluxes to obtain yields of production of their direct precursor reach- ing 0.50 , which is very high considering the complexity of the pathway. The next step, currently investigated deals with the dehydration the hydroxylated lactone.

\section{Acknowledgements}

This work was partly supported by the Région Bourgogne, the Programme of the French Agency for Research ANR "Transaronat" and the Programme d'Actions Universitaires Intégrées LusoFrançaises (PAUILF-CRUP). E. Escamilla-García was granted by the Consejo Nacional de Ciencia y Tecnología (Conacyt-Mexico). We thank C. Bernard-Rojas and the team of IBB-Institute for Biotechnology and Bioengineering, Centre for Biological Engineering, Universidade do Minho, for technical help and Sean O'Riordan for revising the English version of the manuscript.

\section{References}

[1] A. Endrizzi, Y. Pagot, A. Le Clainche, J.-M. Nicaud, J.-M. Belin, Crit. Rev. Biotechnol. 16 (1996) 301-329.

[2] Y. Waché, M. Aguedo, J.-M. Nicaud, J.-M. Belin, Appl. Microbiol. Biotechnol. 61 (2003) 393-404.

[3] I.L. Gatfield, M. Güntert, H. Sommer, P. Werkhoff, Chem. Mikrobiol. Technol. Lebensm. 15 (1993) 165-170.

[4] Y. Waché, M. Aguedo, A. Choquet, I. Gatfield, J.-M. Nicaud, J.-M. Belin, Appl. Environ. Microbiol. 67 (2001) 5700-5704.

[5] J. Beekwilder, I.M. van der Meer, O. Sibbesen, M. Broekgaarden, I. Qvist, J.D. Mikkelsen, R.D. Hall, Biotechnol. J. 2 (2007) 1270-1279.

[6] Y. Bezman, I. Bilkis, P. Winterhalter, P. Fleischmann, R.L. Rouseff, S. Baldermann, M. Naim, J. Agric. Food Chem. 53 (2005) 9199-9206.

[7] G. Feron, G. Mauvais, F. Martin, E. Semon, C. Blin-Perrin, Lett. Appl. Microbiol. 45 (2007) 29-35.

[8] M.H. Ly, L. Cao Hoang, J.-M. Belin, Y. Waché, Biotechnol. J. 3 (2008) $220-225$.

[9] C.J. Puglisi, M.A. Daniel, D.L. Capone, G.M. Elsey, R.H. Prager, M.A. Sefton, J. Agric. Food Chem. 53 (2005) 4895-4900.

[10] J.A. Rocha-Valadez, M. Hassan, G. Corkidi, C. Flores, E. Galindo, L. SerranoCarreon, Biotechnol. Bioeng. 91 (2005) 54-61.

[11] E. Rodriguez-Bustamante, S. Sanchez, Crit. Rev. Microbiol. 33 (2007) 211-230.

[12] M. Aguedo, N. Gomes, E. Escamilla Garcia, Y. Waché, M. Mota, J.A. Teixeira, I. Belo, Biotechnol. Lett. 27 (2005) 1617-1621.

[13] N. Gomes, M. Aguedo, J.A. Teixeira, I. Belo, Biochem. Eng. J. 35 (2007) 380-386.

[14] E. Escamilla García, J.-M. Belin, Y. Waché, J. Appl. Microbiol. 103 (2007) 1508-1515.

[15] E. Escamilla García, J.-M. Nicaud, J.-M. Belin, Y. Waché, Biotechnol. J. 2 (2007) 1280-1285.

[16] Y. Waché, C. Laroche, K. Bergmark, C. Moller-Andersen, M. Aguedo, M.-T. Le Dall, H. Wang, J.-M. Nicaud, J.-M. Belin, Appl. Environ. Microbiol. 66 (2000) 1233-1236.

[17] V. Linek, P. Benes, V. Vacek, Chem. Eng. Technol. 12 (1989) 213-217.

[18] A. Groguenin, Y. Waché, E. Escamilla Garcia, M. Aguedo, F. Husson, M. LeDall, J. Nicaud, J. Belin, J. Mol. Catal. B 28 (2004) 75-79.

[19] K. Bartlett, R. Hovik, S. Eaton, N.J. Watmough, H. Osmundsen, J. Biochem. 270 (1990) 175-180.

[20] Y. Waché, Y. Pagot, J.-M. Nicaud, J.-M. Belin, J. Mol. Catal. B 149 (1998) 165-169.

[21] J. Bremer, A.B. Wojtczak, Biochim. Biophys. Acta 280 (1972) 515-530.

[22] W.S. Kunz, Biochim. Biophys. Acta 932 (1988) 8-16.

[23] C.W. van Roermund, Y. Elgersma, N. Singh, R.J. Wanders, H.F. Tabak, EMBO J. 14 (1995) 3480-3486.

[24] P.P. van Veldhoven, W.W. Just, G.P. Mannaerts, J. Biol. Chem. 262 (1987) 4310-4318.

[25] C.L. Flores, C. Rodriguez, T. Petit, C. Gancedo, FEMS Microbiol. Rev. 24 (2000) 507-529. 